\title{
Article
}

\section{Aeroacoustics Assessment of an Hybrid Aircraft Configuration with Rear-Mounted Boundary Layer Ingested Engine}

\author{
Francesco Petrosino ${ }^{1, * \mathbb{D}}$, Mattia Barbarino ${ }^{1}$ and Martin Staggat ${ }^{2}$ \\ 1 CIRA Italian Aerospace Research Center, 81043 Capua, Italy; m.barbarino@cira.it \\ 2 DLR German Aerospace Center, Engine Acoustics, 10623 Berlin, Germany; martin.staggat@dlr.de \\ * Correspondence: f.petrosino@cira.it
}

check for updates

Citation: Petrosino, F.; Barbarino, M.;

Staggat, M. Aeroacoustics

Assessment of an Hybrid Aircraft Configuration with Rear-Mounted Boundary Layer Ingested Engine. Appl. Sci. 2021, 11, 2936. https:// doi.org/10.3390/app11072936

Academic Editor: Roberto Camussi

Received: 11 February 2021

Accepted: 22 March 2021

Published: 25 March 2021

Publisher's Note: MDPI stays neutral with regard to jurisdictional claims in published maps and institutional affiliations.

Copyright: (c) 2021 by the authors. Licensee MDPI, Basel, Switzerland. This article is an open access article distributed under the terms and conditions of the Creative Commons Attribution (CC BY) license (https:// creativecommons.org/licenses/by/ $4.0 /)$.

\begin{abstract}
Hybrid electric propulsion is a promising solution to reduce aircraft emissions, thus improving the sustainability of the air transport. In this work, a hybrid aircraft configuration with a rear-mounted boundary layer ingestion (BLI) engine has been investigated. The partial embedding of the engine into the fuselage generates a distortion of the ingested inflow causing additional tonal and broadband BLI noise sources, and, at the same time, alters the existing one, such as the rotor-stator interaction noise (RSI). This work is focused on the tonal RSI noise modeling, with and without the distortion generated by the BLI, and the far-field propagation including the acoustic masking contribution due to the engine-fuselage integration. As the main result, this work shows the contributions of BLI and the engine-aircraft integration on the RSI noise. Both effects should be properly taken into account in the early aircraft design stage for an effective noise reduction even at ground level.
\end{abstract}

Keywords: aeroacoustics; boundary layer ingestion; acoustic scattering; engine noise

\section{Introduction}

Environmental problems are becoming more and more evident in all human fields. In the aerospace world, the rapid growth of air and urban traffic has prompted Government commissions, the scientific community, and manufacturers to invest resources to reduce the environmental impact of their systems. Electric propulsion has been recognized as one of the most promising approaches for reducing emissions, such as noise and pollutants. However, electrified transport configurations will bring forward novel issues. Innovative aircraft configurations including alternative propulsion systems should be investigated in order to achieve the 2050 goals established by the European Commission [1], that is, among the others, of $65 \%(-15 \mathrm{EPNdB})$ for noise reduction [2]. In this context, all benefits expected from electric propulsion require a close coupling of a detailed aircraft design with a dedicated propulsion system. Electric propulsion enables innovative aircraft (A/C) configurations, promoting overall performance advantages:

- Distributed Electric Propulsion (DEP), where electric engines are distributed along the wing span, enhancing significantly the wing lift property.

- Boundary Layer Ingestion (BLI), where engines, thanks to their partial integration to the fuselage, diminish the $\mathrm{A} / \mathrm{C}$ drag.

More specifically, BLI propulsion systems aim at reducing the required propulsive power compared to conventional tube-and-wing configurations [3]. For ducted fans, the propulsive benefit is based on two possibilities: reducing the overall aircraft mass and drag, due to the nacelle pylon removal and the lower wetted surface area, and reducing the power dissipation in the flow field, by reducing the exhaust jet wasted kinetic energy and filling-in the airframe wake velocity defect. However, the fuselage boundary layer ingestion leads to the partial loss of the fan inflow axial uniformity, thus causing a strong azimuthal variation of the fan blade loading with aerodynamic and aeroacoustic drawbacks. 
The interaction of the incoming boundary layer via the propulsion intake with fan rotor (BLI-ducted fan configuration), in which a set of potential noise generation mechanisms are the main concerns to explore at different flight conditions in relation to BLI-triggered aerodynamic flow phenomena [4]. Moreover, propeller noise is also strongly affected by an interaction of the propeller tip passing through any airframe boundary layer (BLI-propeller configuration) [5].

In addition to working on the noise generation mechanisms, a proper engine-aircraft integration and the design of unconventional configurations would play a critical role to reduce the overall noise at airport thanks to the acoustic masking by the aircraft. BlendedWing-Body (BWB) configurations with engines mounted on the upper surface of the aft center body represent a potential solution for improving the masking effects $[6,7]$.

In the aforementioned framework, this work aims at assessing the noise generated at ground level by a turboelectric aircraft with an aft boundary layer propulsor (Section 2) through a comprehensive approach involving low and mid-fidelity Computational AeroAcoustics (CAA) methods (Section 3). The paper shows the impact of the BL ingested on the Rotor-Stator Interaction (RSI) noise when the fan stage is properly designed against a distorted flow, mainly considering the influence of the engine-aircraft integration on the noise propagation at ground level (Section 4).

\section{BLI Aircraft Configuration Description}

A single-aisle turboelectric aircraft with an aft boundary layer propulsor was considered as a possible concept configuration that takes advantage of engine ingestion of fuselage boundary layer, see Figure 1. This vehicle configuration was used for typical transonic transport flight, having a low wing with T-tail architecture [8]. The under wing nacelles have been not considered. The wing has influence on the development of the boundary layer along the fuselage, particularly when the angle of incidence changes. It should be considered that the flow behavior in the rear part of the fuselage is affected by the wing position, setting, and wing-fuselage fairing. The rear nacelle inlet ingests the boundary layer coming from the vertical tail plane. The horizontal tail plane is far from the BLI propulsor inlet, perhaps not affecting the boundary layer characteristics for the present study.

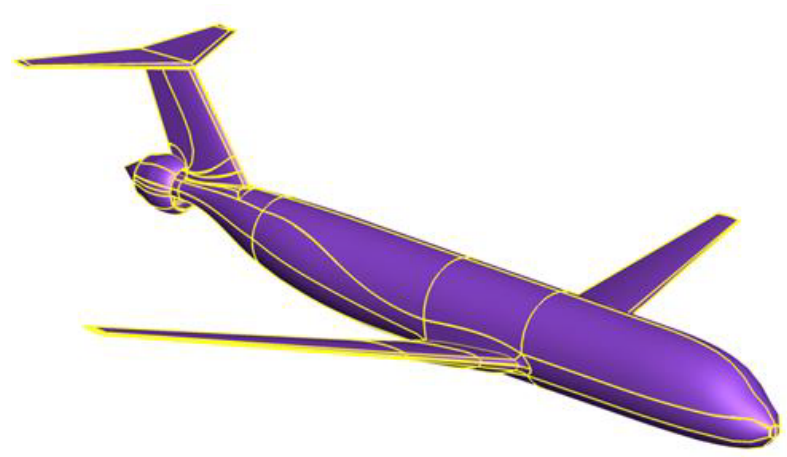

Figure 1. Aircraft configuration geometry.

\section{Aeroacoustic Model}

The noise prediction at ground level of an aircraft configuration with aft boundary layer propulsor requires the use of a comprehensive approach encompassing from the noise source to the far-field propagation modeling. A comprehensive approach including low- and mid-fidelity methods for the aeroacoustic assessment is hear-after described. The approach consists of

- $\quad$ engine noise source and in-duct propagation models (Section 3.1),

- $\quad$ acoustic free-field and scattering models (Sections 3.2.1 and 3.2.2), and

- far-field environmental acoustic model (Section 3.2.3). 


\subsection{Engine Acoustic Source Model}

The modeling of the RSI noise and the impact of the inflow distortion on this noise source is model-led and investigated, whereas, the modeling of the boundary layer interaction noise is not a subject of the present study.

The engine acoustic source modeling can be subdivided into three successive steps: the actual source modeling informed by computational fluid dynamics (CFD); the propagation of the modal solution of the sound field to the engines inlet and outlet plane; and finally the computation of all necessary physical quantities, which are required as boundary conditions for the BEM solver, i.e., the reconstruction of the sound pressure and its normal derivative based on the propagated modal solution.

\subsubsection{Aerodynamic Excitation Modelling}

The engine noise modeling has been performed by the tool PropNoise. The tool is a DLR in-house code developed at DLR's department of engine acoustics during the last fourteen years [9]. The acoustic modules of the tool use an analytical theory utilizing circumferential modes in frequency domain. Based on the known aerodynamic excitation, PropNoise allows the prediction of several tonal and broadband engine noise sources, such as self- or interaction noise. One of the most recent extensions of the code enable PropNoise to account for boundary layer rotor interaction noise [10]. The aerodynamic excitation can be estimated by the tool itself, using a mean-line approach or alternatively by aerodynamic measurement or high-fidelity CFD-RANS computations.

In the present study, the RANS-informed operation mode of PropNoise, as shown in Figure 2 (CFD-informed PropNoise), is used. This ensures a highly accurate prediction of the RSI noise source and its underlying source mechanism. DLR's flow solver TRACE [11] was used to compute the turbulent flow within the turbomachinery. This step is given by the box "3D RANS flow solution" in Figure 2. Here, the compressible Navier-Stokes equations are solved in the relative system of the rotor and stator. This flow solver was specifically developed for calculating the flow in turbomachinery applications. In a next step, the mean and turbulent flow quantities, such as the rotor wakes, responsible for the RSI noise mechanism, as well as geometrical parameters, such as leading and trailing edge positions, are extracted (step "Extraction of flow and geometry" in Figure 2) and used to reconstruct the aerodynamic excitation of RSI noise at the stator vane leading edges (step "Reconstruction of aerodyn. excitation" in Figure 2). The process of extraction and reconstruction is done according to Jaron [12].

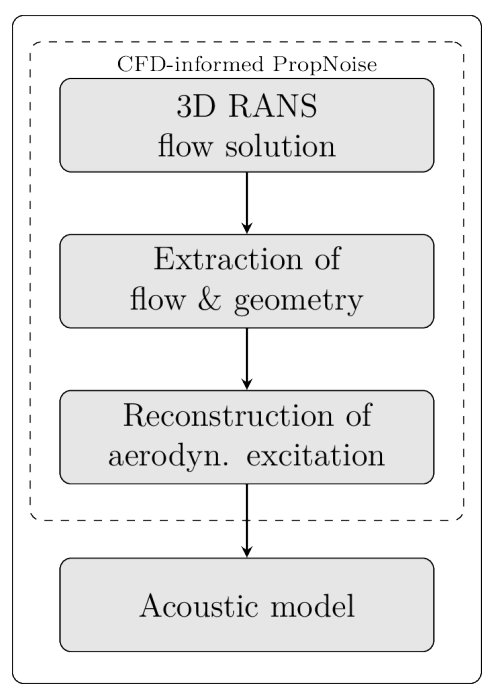

Figure 2. PropNoise workflow for standalone and computational fluid dynamics (CFD)-informed modes. 


\subsubsection{Acoustic RSI Noise Source Model}

As mentioned, only the tonal RSI noise mechanism is considered in the present study. The physical background of the mechanism is illustrated in Figure 3: due to wall adhesion, a turbulent boundary layer is formed on the pressure and suction side of the rotor blade. When passing the rotor blade trailing edge, these boundary layers merge and form a wake shear flow, which propagates towards the stator vane leading edge. The mean velocity deficit of the wake causes a periodic fluctuation of the inflow incidence angle at the stator vane leading edge and therefore a periodic fluctuation of the lift force. This fluctuation of the lift force results in tonal noise at the blade passing frequency (BPF) and its higher harmonics. The focus on this noise source is justified by the fact that the rotor is operating at subsonic conditions as shown in Table 1. Thus, no shock noise is generated. Other tonal self-noise sources, such as steady drag, steady lift, and thickness noise, are cut-off for a subsonic ducted rotor [13]. The turbulence, contained in the wakes, additionally excites broadband noise at the stator vane leading edge. However, in the context of this work, only the tonal RSI mechanism is considered. Note that the turbulent wakes are extracted from the numerical simulation at the mixing plane. Using the assumption of stationary and circumferential uniform rotor wakes, the propagation of the wakes towards the stator leading edge is performed according to Jaron [12].

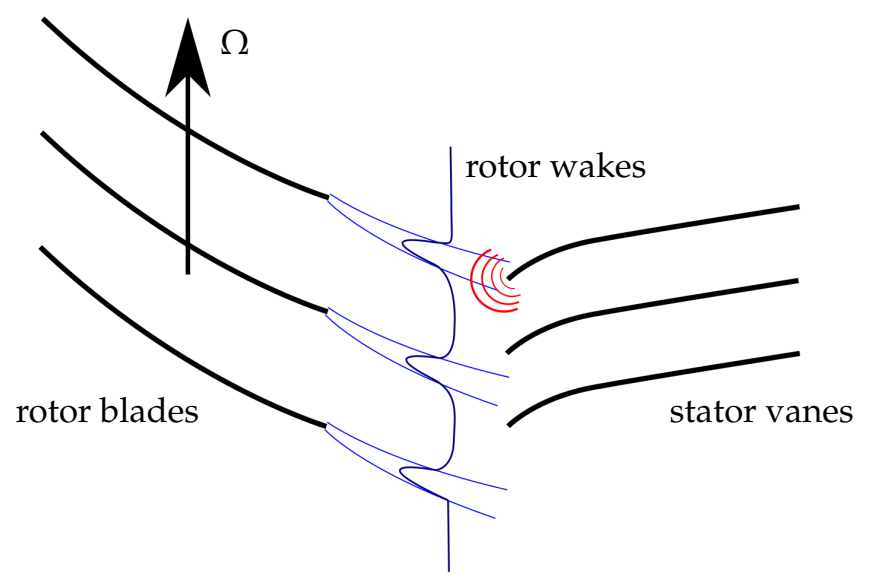

Figure 3. Illustration of Rotor-Stator Interaction (RSI) noise mechanism.

Table 1. Aerodynamic and engine conditions.

\begin{tabular}{cc}
\hline Variable & Value \\
\hline Mach flight & 0.78 \\
Mach rotor tip & 0.60 \\
Altitude & $10,363.2 \mathrm{~m}$ \\
Engine Mass Flow & $99.45 \mathrm{~kg} / \mathrm{s}$ \\
Engine Rotational Speed & $2500 \mathrm{RPM}$ \\
\hline
\end{tabular}

Following Moreau [9], the modal amplitudes, consisting of the azimuthal and radial mode orders $m$ and $n$, of the tonal RSI noise are given by

$$
A_{m n}^{ \pm}=V \int g_{m n}(\omega) \cdot \mathcal{R}(\omega) \cdot \Psi(\omega) \cdot \zeta(\tilde{\omega}) \cdot \exp \left(i k_{x} x_{L E}+i m \theta_{L E}\right) \cdot \mathrm{d} r_{s}
$$

In Equation (1), the parameter $V$ denotes the stator vane count, $g_{m n}$ is the Green's function for an infinitely long annular channel, and $k_{x}$ the axial acoustic wave number. 
Note that the subscript $L E$ denotes the stator vane leading edge position and the subscript $s$ the position of the source. This function is given by [9]

$$
g_{m n}\left(x, r, r_{s}, \omega\right)=\frac{J_{m}\left(k_{r} r\right)+Q_{m n} Y_{m}\left(k_{r} r\right)}{\sqrt{F_{m n}}} \exp \left(-i k_{x}^{ \pm} x\right) \cdot \frac{i}{4 \pi R} \cdot \frac{J_{m}\left(k_{r} r_{s}\right)+Q_{m n} Y_{m}\left(k_{r} r\right)}{k R \alpha_{m n} \sqrt{F_{m n}}}
$$

With the acoustic wave number in radial direction $k_{r}$, radial position $r$, the Bessel function of first and second kind $J_{m}$ and $Y_{m}$, the cut-on factor $\alpha_{m n}$, and the outer radius $R$ of the annular channel. Note that the quantity $Q_{m n}$ models the impact of the hub body and is zero in case of its absence. The quantity $F_{m n}$ is a normalization factor $[9,12,14]$.

The term $\mathcal{R}=i k_{n} c$ in Equation (1) models the radiation efficiency of the sound source from the blade surface. Note that $k_{n}$ is the acoustic wave number in normal direction to the blade surface and $c$ the chord length of the blade. For the acoustic modeling, all blades and vanes are assumed to be flat plates [9].

The parameter $\Psi(\omega)$ models the dimensionless source distribution along the chord and is given by

$$
\Psi(\omega)=\frac{1}{c} \int_{l=0}^{c} h_{L}(l) \exp \left(-i k_{l} l\right) \mathrm{d} l,
$$

with the acoustic wave number in direction of the blade chord $k_{l}$ and $h_{L}(l)$ the nondimensional distribution of the blade loading along the chord with the maximum load at the leading edge of the blade [9].

Finally, the aerodynamic excitation $\zeta(\tilde{\omega})$ is given by

$$
\zeta(\tilde{\omega})=\frac{1}{2} \rho_{0} W_{0}^{2} C_{L}(\tilde{\omega}) \exp \left(i \phi_{0}\left(r_{s}, \tilde{\omega}\right)\right) .
$$

Figure 4 illustrates the used coordinate system for the acoustic model given by Equations (1)-(4).

Note that $\tilde{\omega}$ is the frequency occurring in the relative or rotating frame of reference, $\rho_{0}$ the density of air, $W_{0}$ the relative velocity at the stator vane, and $C_{L}(\tilde{\omega})$ the instationary lift coefficient. For completeness, note that the phase term $\phi_{0}\left(r_{s}, \tilde{\omega}\right)$ allows the modeling of a delay in excitation and is thus useful, e.g., for the consideration of curved wakes.

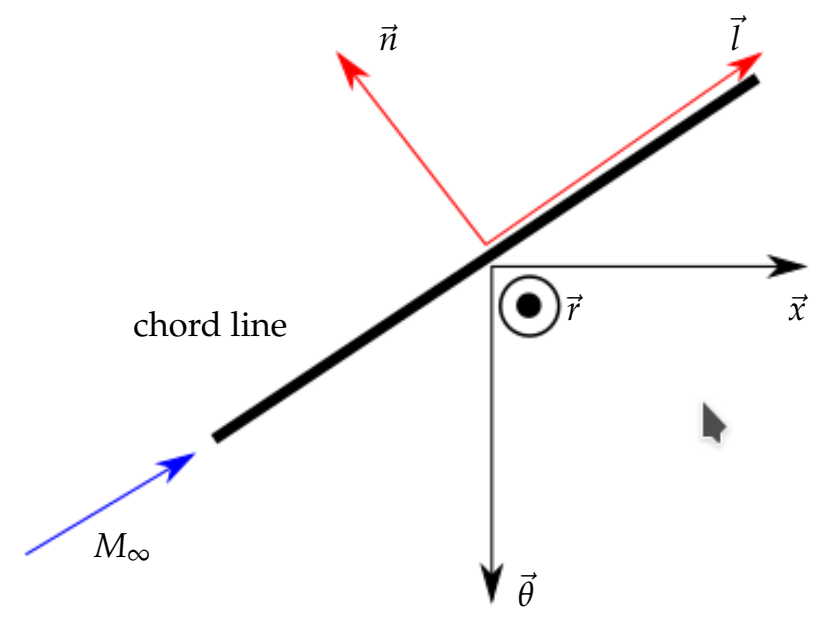

Figure 4. Illustration of used coordinate system of the acoustic engine noise model.

\subsubsection{Noise towards the Engines Inlet and Outlet Plane}

The sound field, calculated in the form of a modal solution at the point of origin, has to be propagated to the inlet and outlet planes of the engine. At these planes, the radiation of the sound into the far-field takes place. In this process of propagation from the origin to the inlet or outlet planes, the acoustic modes change their complex amplitude and propagation capability as a function of the altering geometry and flow conditions. 
The propagation is computed according to Jaron [12] between the locations 1 and 2. Here, the assumption is made that the acoustic power for a mode pair $(m, n)$ remains constant as long as it remains cut-on, i.e., its cut-on factor $\alpha_{m, n}$ is a real number. The new amplitude at location 2 reads

$$
A_{m n_{2}}^{ \pm}=A_{m n_{1}}^{ \pm}\left(\frac{R_{1}}{R_{2}} \sqrt{\frac{\rho_{0_{2}} a_{0_{2}} \tilde{k}_{2}}{\rho_{0_{1}} a_{0_{1}} \tilde{k}_{1}}} \sqrt{\frac{\alpha_{m n_{1}}}{\alpha_{m n_{2}}}} \frac{\left(1-M_{x_{1}}^{2}\right)}{\left(1-M_{x_{2}}^{2}\right)} \frac{\left(1 \mp \alpha_{m n_{2}} M_{x_{2}}\right)}{\left(1 \mp \alpha_{m n_{1}} M_{x_{1}}\right)}\right) \exp \left(i \int_{1}^{2} k_{x}^{ \pm} \cdot \pm|\mathrm{dx}|\right)
$$

In Equation (5), the speed of sound is given by $a_{0}, \tilde{k}$ is the free-field wave number, and $M_{x}$ is the axial Mach number. Note that the exponential term accounts for the propagation of acoustic modes in a slowly varying duct. Equation (5) clarifies that the propagation only accounts for a scaling of the modal pressure due to a change of the cross section under the assumption of a constant modal power and a filtering of cut-on/cut-off modes. Note that a scattering of power into different radial and circumferential mode orders during propagation is not modeled. For more detail see Jaron [12].

\subsubsection{Computation of Boundary Conditions}

The coupling of the in-duct acoustic propagation model with the external one is achieved through a dedicated boundary conditions written in terms of acoustic pressure $p(r, \theta)$ and its normal derivative $\partial p(r, \theta) / \partial n$. Once the modal solution is known at the engines inlet and outlet plane, the sound pressure field $p(r, \theta)$ and its normal derivative $\partial p(r, \theta) / \partial n$ in frequency domain can be easily computed by Equation (6):

$$
p^{\omega}(x, r, \theta)=\sum_{m=-\infty}^{\infty} \sum_{n=0}^{\infty} A_{m n}^{ \pm} \frac{J_{m}\left(k_{r} r\right)+Q_{m n} Y_{m}\left(k_{r} r\right)}{\sqrt{F_{m n}}} \exp \left(i k_{x}^{ \pm} x+i m \theta\right)
$$

As the normal vector points either in the x-direction (engine outlet plane) or against the $x$-direction (engine inlet plane), the normal derivative of the sound pressure field is given by Equation (7):

$$
\begin{aligned}
\frac{\partial p^{\omega}(x, r, \theta)}{\partial n} & = \pm \frac{\partial p^{\omega}(x, r, \theta)}{\partial x} \\
& = \pm i k_{x}^{ \pm} \sum_{m=-\infty}^{\infty} \sum_{n=0}^{\infty} A_{m n}^{ \pm} \frac{J_{m}\left(k_{r} r\right)+Q_{m n} Y_{m}\left(k_{r} r\right)}{\sqrt{F_{m n}}} \exp \left(i k_{x}^{ \pm} x+i m \theta\right)
\end{aligned}
$$

It should be noted that Equations (6) and (7) have to be evaluated for $x=0$, as the modal amplitudes $A_{m n}^{ \pm}$already include the effect of propagation from a location 1 (source) to a location 2 (inlet/outlet plane) according to Equation (5).

\subsection{Propagation Model}

The aeroacoustics propagation model is based on the numerical solution of the acoustic analogy equation proposed by J. Lighthill in 1952 [15,16], and more developed in the succeeding works of Howe [17], Pierce [18], and Morris [19]. The frequency domain counterpart of the aforementioned analogy equations leads to a convected Helmholtz equation which results in an integral equation numerical handled with a Boundary Element Method (BEM). The convected Helmholtz equation reads

$$
\nabla^{2} h\left(x, x_{q}\right)-(-i k+\mathbf{M} \cdot \nabla)^{2} h\left(x, x_{q}\right)=q\left(x_{q}\right)
$$

where $h$ represents the acoustic pressure $p$ or the scalar velocity potential $\varphi, q$ the source term, $k=2 \pi / \lambda$ the wave number, and $\mathbf{M}=v / c$ is the Mach number of the fluid with uniform velocity $v$. In the potential formulation, the acoustic pressure $p$ reads

$$
p(x)=\rho c(i k \varphi(x)-\mathbf{M} \cdot \nabla \varphi(x))
$$


As extensively reported in several works [20-22], exploiting the free-field Green's function, the boundary integral formulation of Equation (8) reads

$$
\begin{aligned}
C h\left(x, x_{q}\right)=\int_{V} g(x, y) q\left(y, x_{q}\right) d V(y) & +\oint_{S} B_{1}\left(x, x_{s}\right) h\left(x_{s}, x_{q}\right) d S\left(x_{s}\right) \\
& +\oint_{S} B_{2}\left(x, x_{s}\right) \frac{\partial h}{\partial n}\left(x_{s}, x_{q}\right) d S\left(x_{s}\right)
\end{aligned}
$$

where $x, x_{q}$, and $x_{s}$ are the position of the observer, the sources, and the points on the surface $S$, respectively; $C$ is a coefficient that depends on the location of the point $x$ (it is 1 in the flow, $1 / 2$ on the boundary surface and 0 inside the surface); and the functions $B_{1}\left(x, x_{s}\right)$ and $B_{2}\left(x, x_{s}\right)$ are given by

$$
\begin{aligned}
& B_{1}\left(x, x_{s}\right)=\left(2 i k M_{n} g+\left[M_{n} \mathbf{M}-n\right] \cdot \nabla g+\nabla_{t g} \cdot\left[g M_{n} M_{t g}\right]\right) \\
& B_{2}\left(x, x_{s}\right)=\left(1-M_{n}^{2}\right) g
\end{aligned}
$$

where the tangential divergence $\nabla_{t g} \cdot\left[g M_{n} M_{t g}\right]=M_{n}\left[M_{t} \frac{\partial g}{\partial t}+M_{s} \frac{\partial g}{\partial s}\right]$, involves the directional derivatives and the Mach number components along the $s$ and $t$ directions lying in the plane orthogonal to the normal unit vector defined positive pointing into the fluid, and $g$ is the convected free-field green function as expressed in [23]:

$$
g\left(x, x_{s}\right)=\frac{1}{4 \pi R^{*}} e^{i k\left(R^{*}+M \cdot\left(x-x_{s}\right)\right) / \beta^{2}}
$$

where

$$
\begin{aligned}
R^{*} & =\sqrt{\beta^{2}\left|x-x_{s}\right|^{2}+\left(M \cdot\left(x-x_{s}\right)\right)^{2}} \\
\beta & =\sqrt{1-M^{2}}
\end{aligned}
$$

The $\int_{V} g(x, y) q\left(y, x_{q}\right) d V(y)$ term of Equation (10) represents the incident field generated at an observer point, $x$, by a generic source, $q$, located in $x_{q}$. This can be reviewed as a generic incident solution, $h_{i n c}\left(x, x_{q}\right)$, provided by an external solver. Assuming this generalized incident field, the Equation (10) can be written as

$$
\begin{aligned}
C h\left(x, x_{q}\right)=h_{i n c}\left(x, x_{q}\right) & +\oint_{S} B_{1}\left(x, x_{s}\right) h\left(x_{s}, x_{q}\right) d S\left(x_{s}\right) \\
& +\oint_{S} B_{2}\left(x, x_{s}\right) \frac{\partial h}{\partial n}\left(x_{s}, x_{q}\right) d S\left(x_{s}\right)
\end{aligned}
$$

that allows to solve a generalized scattering problem.

ACO-FAM is an ACOustic FAst Multipole code developed at CIRA's department of computational acoustics [24]. ACO-FAM implements the aforementioned integral boundary element formulation for the solution of interior and exterior acoustic problems (radiation and scattering) and solves the inverse problem through a collocation Boundary Element Method (BEM) accelerated with an Adaptive black-box Fast Multipole approach (AbbFMM).

\subsubsection{Free-Field Propagation Model}

The Boundary Integral Equation (14) (BIE) with $C=1$ can be used to compute the acoustic field $h(x)$ at any point, $x$, by the knowledge of $h\left(x_{\text {SURF }}\right)$ and $\frac{\partial h\left(x_{\text {SURF }}\right)}{\partial n}$ on a surface SURF that is encompassing the noise source, $q$. In absence of any other source point, a free-field propagation model, i.e., the incident field, can be achieved by the Equation (14) as

$$
h_{\text {inc }}\left(x, x_{q}\right)=\oint_{S} B_{1}\left(x, x_{S U R F}\right) h\left(x_{S U R F}, x_{q}\right) d S\left(x_{S U R F}\right)+\oint_{S} B_{2}\left(x, x_{S U R F}\right) \frac{\partial h}{\partial n}\left(x_{S U R F}, x_{q}\right) d S\left(x_{S U R F}\right)
$$

where the term $h\left(x_{S U R F}, x_{q}\right)$ and its derivative correspond to the acoustic solution at the inlet and outlet of the engine as provided by the engine noise model of Section 3.1.4. 


\subsubsection{Scattering Model}

The scattering problem through the BIE (14) is solved by assuming the coefficient $\mathrm{C}=1 / 2$, and solving the problem on the surface body, $S$. According to the collocation approach, the Equation (14) reads

$$
\begin{array}{r}
\frac{1}{2} h\left(x_{s}, x_{q}\right)=h_{i n c}\left(x_{s}, x_{q}\right)+\oint_{S} B_{1}\left(x_{s}, x_{s}\right) h\left(x_{s}, x_{q}\right) d S\left(x_{s}\right) \\
+\oint_{S} B_{2}\left(x_{s}, x_{s}\right) \frac{\partial h}{\partial n}\left(x_{s}, x_{q}\right) d S\left(x_{s}\right)
\end{array}
$$

where the unknowns terms are the function $h\left(x_{s}\right)$ and its derivative, while the incident noise field, $h_{i n c}$, is the known term computed with Equation (15).

The discretization of the above equation leads to a system of $\mathrm{N}$ algebraic equations with $2 \mathrm{~N}$ unknowns, where $\mathrm{N}$ is the number of elements that can be solved introducing $\mathrm{N}$ boundary condition equations expressed as a linear relation between $h$ and $\frac{\partial h}{\partial n}$. A generalized boundary condition reads

$$
\alpha(x) \frac{\partial h}{\partial n}\left(x, x_{q}\right)+\beta(x) h\left(x, x_{q}\right)=\gamma(x)
$$

In the case of a soft and vibrating wall in absence of mean flow, the boundary condition of Equation (17) assume the pressure-based formulation

$$
\frac{\partial p}{\partial n}=-i k \frac{\rho c}{Z} p+i k \rho c V_{n}
$$

where $Z$ is the acoustic impedance and $V_{n}$ is the vibrating wall normal velocity. Once the inverse problem is solved, the total acoustic field is computed with the BIE (14), assuming $\mathrm{C}=1$. The collocation approach here discussed has been implemented in CIRA code [22] where the stability of the algebraic system is ensured with the CHIEF algorithm [25], consisting in adding a set of $\mathrm{M}$ points internal to the scattering bodies, in which the sought function is null. It leads to a system of $2 \mathrm{~N}+\mathrm{M}$ equations with $2 \mathrm{~N}$ unknowns that needs to be solved with a least-square technique. The internal points are collocated with a stochastic procedure within the scattering body [26] and a robust Oct-tree algorithm [24]. In order to reduce the computational and memory cost of the dense-matrix related to the BEM approach, an Adaptive black-box Fast Multipole Method with Chebyshev polynomial interpolation (AbbFMM) has been implemented [24].

\subsubsection{Ground Propagation Noise Model}

ACO-ENV is an ENVironmental ACOustic tool developed by CIRA's department of computational acoustics that allows analyzing the environmental acoustic impact of novel configurations once their acoustic behavior is characterized at source level.

The code, based on the Quasi-Static Acoustic approach [27,28], considers an acoustic database (ADB) as input and propagates the acoustic field on the ground through a ray tracing technique. The ADB is made up of far-field acoustic hemispheres, computed by the above-mentioned propagation model, able to reproduce the acoustic source in terms of three-dimensional directivity pattern and covering the whole trimming conditions needed during the flight trajectory. The code also accounts for sound propagation in compliance with UNI-ISO 9613-2:2006, atmospheric absorption according to SAE ARP866B [29], several acoustic metrics (e.g., Sound Exposure Level, LAmax, and EPNL) and it is also able to compute multiple events analyses. 
The code needs of the following input:

- Ambient conditions.

- Segmentation of the aircraft flight trajectory in terms of global cartesian coordinates of the center, velocity, and flight path angle.

- Acoustic database of hemispheres covering the trajectory conditions in terms of velocity and flight path angle and reporting the Sound Pressure Level (SPL) in narrowor third-octave bands.

- A carpet of observation points for the acoustic footprint generation.

For each flight segment in terms of velocity and flight path, the corresponding source hemisphere is carried out by a bilinear interpolation over the acoustic database. The selected hemisphere is moved to the aircraft center position and a ray is projected to connect each observation point with the hemisphere center. The intersection of the ray with the hemisphere allows selecting the discretized hemisphere panel that includes the intersection point, as shown in Figure 5. The SPL values for each narrow or third-octave band are interpolated from the panel nodes, through an Inverse-distance interpolation algorithm, and propagated according to UNI-ISO 9613-2:2006 and SAE ARP866B.

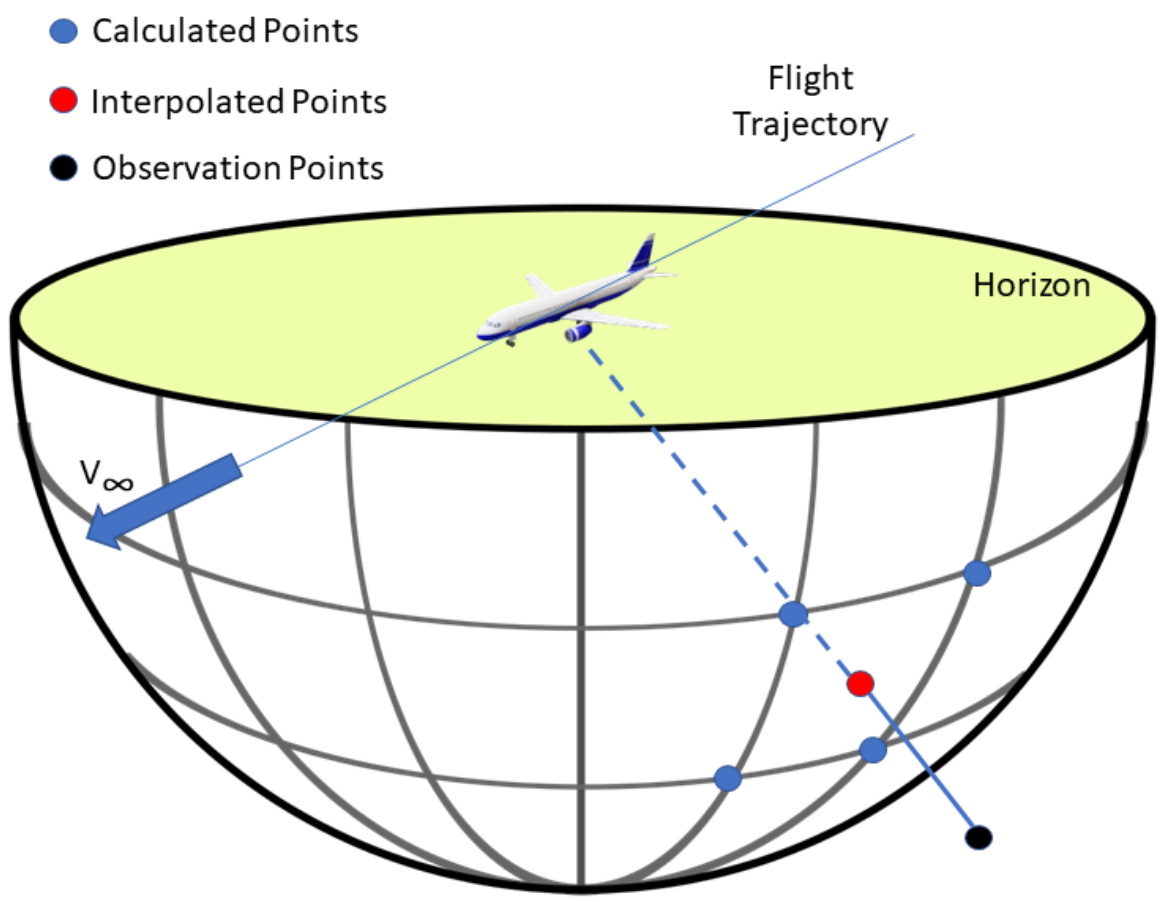

Figure 5. ACO-ENV approach for ray tracing Sound Pressure Level propagation.

The integration over the whole frequency spectrum provides the Overall Sound Pressure Level (OASPL) for each carpet microphone. The process is iterated for each trajectory segment providing, for each microphone, the time history of SPL values and of the (OASPL) in A-weighted scale is used to finally compute the acoustic metrics.

In this work, the Sound Exposure Level (SEL) and the Single Event Level $(L A e q, T)$ in the period $\mathrm{T}$ is finally computed for each microphone as

$$
\begin{gathered}
\text { LAeq, } T=S E L-10 \log \left(T / T_{0}\right) \\
S E L=10 \log \left(\sum_{i=1}^{N} d t_{i} * 10^{S P L A i / 10}\right)
\end{gathered}
$$

where $T$ is the event duration time, $d t_{i}$ is the acoustic observation period of the trajectory segment $\mathrm{i}, \mathrm{N}$ are the number of observation periods that corresponds to the trajectory segments, and $T_{0}$ is a reference time of $1 \mathrm{~s}$. A sketch of the method is available in Figure 6. 


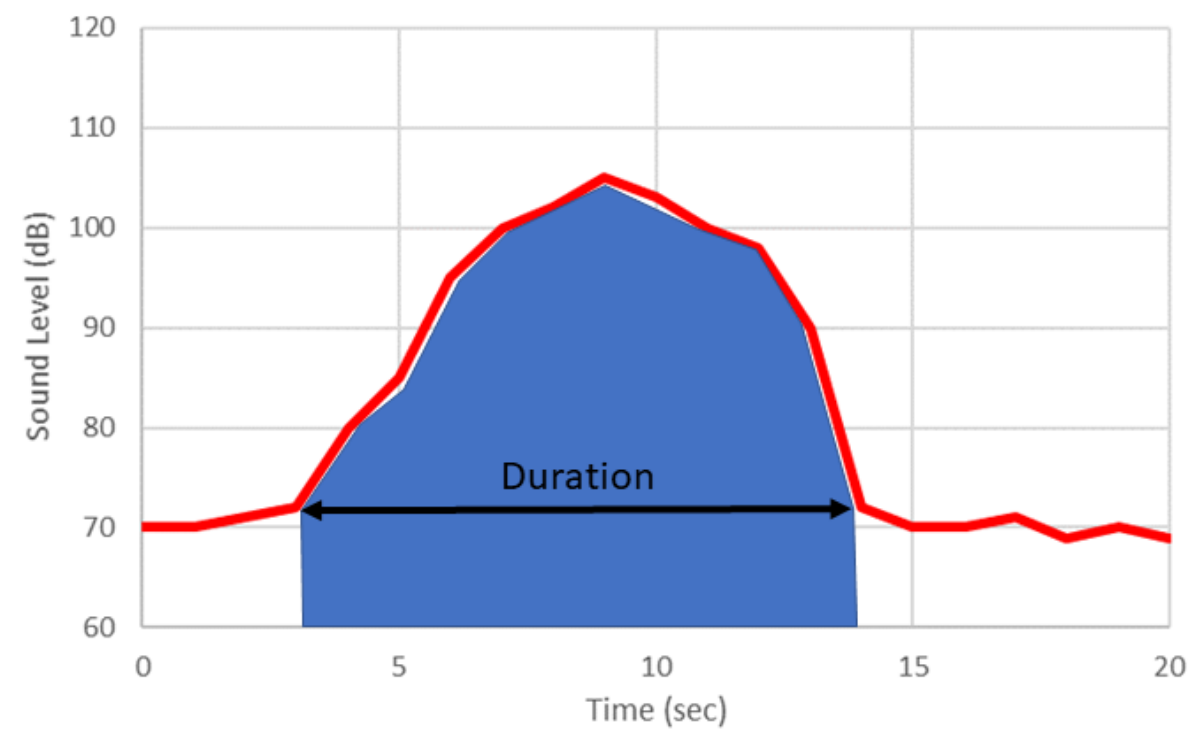

Figure 6. Sound Exposure Level (SEL) calculation procedure from the Overall Sound Pressure Level (OASPL) time history.

\section{Aeroacoustic Results}

The RSI noise of the single-aisle turboelectric aircraft with aft boundary layer propulsor (Figure 1) has been hereafter assessed. The aircraft and engine aerodynamic conditions are in Table 1, while the main engine frequencies analyzed were $1333 \mathrm{~Hz}, 2000 \mathrm{~Hz}, 2666 \mathrm{~Hz}$, and $3333 \mathrm{~Hz}$ corresponding to the 2nd, 3rd, 4th, and 5th blade passage frequency (BPF).

First, the RSI noise has been computed with the procedure of Section 3.1 by modeling the engine fan stage and, then, by propagating the in-duct acoustic field at the inlet and outlet of the engine nacelle. A proper design of the fan-stage has been also performed to account for the BL ingested by the engine.

Second, the external free- and scattered field has been computed with the BEM approach of Section 3.2. A representative part of the scattering body (Figure 1), encompassing the vertical tail, the horizontal tail, and the engine nacelle, has been considered. This fuselage portion of around $10 \mathrm{~m}$ was considered sufficient to capture the main installation effects by, meanwhile, preserving the computational cost.

Finally, the effect of the RSI noise under BLI was evaluated in terms of environmental acoustic impact for a flyover trajectory, according to the procedure proposed by international SAE regulations [30] and the model presented in Section 3.2.3.

\subsection{Engine Noise Source Term}

Figure 7a (left) illustrates the investigated geometry: the fan stage consists of a rotor with 16 blades and a stator with 38 vanes. With a rotor tip radius of $R_{t i p}=0.89 \mathrm{~m}$ and a rotor hub radius of $R_{h u b}=0.56 \mathrm{~m}$, a hub-to-tip ratio $\eta=0.63$ is achieved. For the noise prediction, a symmetric flow in circumferential direction is assumed. The impact of the tail fin structure, shown in Figure 1, is neglected. In this case, no tonal boundary layer rotor interaction noise can be excited at the BPF and its harmonics. However, due to the different noise mechanism, tonal RSI noise is still excited and altered depending on the presence or absence of the inflow distortion. The investigated operating point of the propulsor is given in Table 1. Note that this operating point is the design point of the fan stage.

Due to the circumferential symmetry of the geometry and flow conditions shown in Figure 7a, a periodic boundary condition, completing the domain in azimuthal direction, can be used for the CFD, and the computation of a single rotor-stator passage is sufficient to represent the investigated problem. The resulting computational domain drastically reduces the numerical costs and is exemplary illustrated in Figure $7 \mathrm{~b}$. The domain is 
discretized by approximately 4 mio. cells. Particular attention is paid to ensure that the rotor wake region is meshed in high quality to adequately resolve the rotor wakes causing the RSI noise mechanism. In addition, a non-dimensional wall distance of $y^{+}<1$ is ensured everywhere at the rotor blade and stator vane wall. These walls are modeled as viscid walls. Thus, a no wall-function is used to model the mean velocity gradient within the blade and vane boundary layer. For simplicity, the tip and hub wall of the fan stage are modeled by inviscid walls. In addition, the total temperature $T_{t}$ and total pressure $p_{t}$ have to be given at the inlet plane. The mass-flow is used as boundary condition at the outlet plane. Finally, the rotor block group is assumed to move around the engine axis by the given engine rotational speed $\Omega$, while the stator block group is fixed. The turbulence is modeled by the Menter SST $2003 k-\omega$ model. A second-order Fromm scheme is used for the spatial solution of the equations. The time integration is performed by a second-order backward Euler scheme, using the predictor-corrector method.

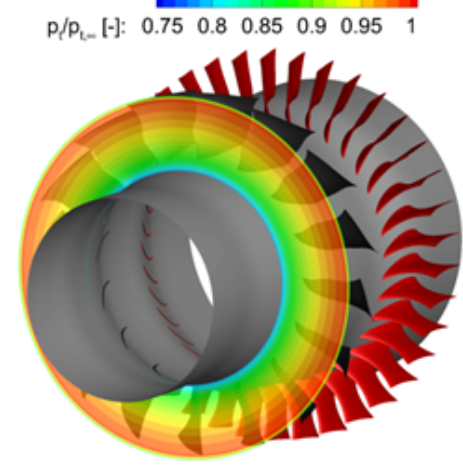

(a)

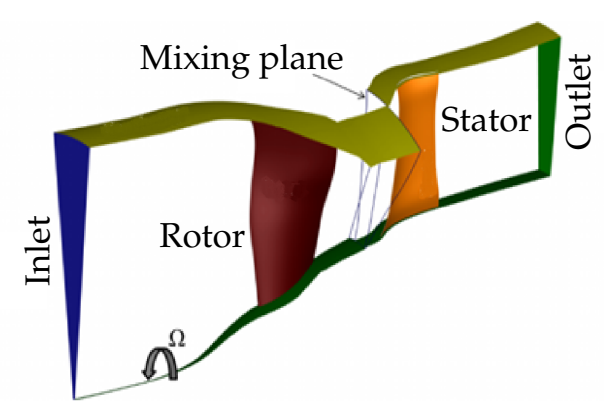

(b)

Figure 7. Illustration of investigated Aft-Propulsor and CFD domain. (a) Exemplary shape of the inflow distortion of Aft-Propulsor configuration. Source: [31], reproduced with permission. (b) Exemplary illustration of single-passage computation domain for CFD. Source: [12], reproduced with permission.

Figure 8a is an exemplary illustration of the inflow distortion entering the AftPropulsor (blue) in comparison with the Clean inflow configuration (red). Note that the boundary layer thickness $\delta_{99}$ slightly exceeds the tip radius [32,33]. Thus, a strong inflow distortion of a boundary layer thickness exceeding 2.5 of the hub-to-tip gap at the rotor is considered. Only the normalized mean velocity profile part of the unhatched region is considered and entering the propulsor. Note that in both cases the same massflow, given in Table 1, is ensured to maintain the operating point of the fan stage. As aforementioned, the total pressure has to be defined at the inlet plane of the rotor block group. The radial varying inflow distortion is defined by the total pressure distortion shown in Figure 8 and used as a radial resolved boundary condition for the CFD computation. The detailed process of defining the boundary layer profile for the considered aircraft configuration is given by Silberhorn et al. [32,33]. For the Clean configuration, the total pressure is assumed to be constant for all radial positions. 


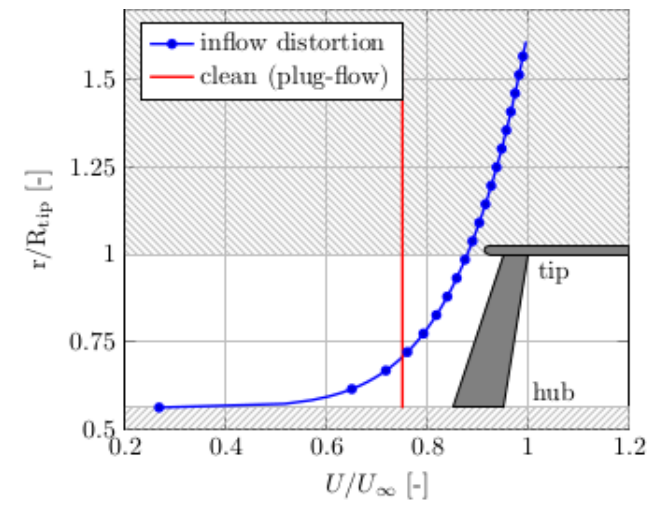

(a)

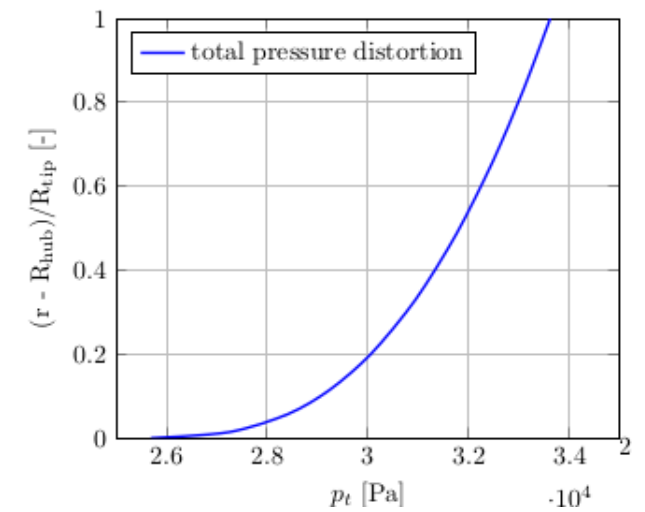

(b)

Figure 8. Illustration and definition of used inflow distortion. (a) Exemplary shape of the inflow distortion and Clean configuration. (b) Used total pressure distortion.

Results for the generated sound power levels (SWL) at the BPF and its higher harmonics of tonal RSI noise are shown in Figure 9a. Due to a cut-off design for RSI noise of the fan stage, the SWL for the BPF itself is zero. For the second to fifth BPF, both configurations show a decreasing trend of SWL for higher harmonics. For the second BPF, the Clean configuration dominates the SWL. For the third to fifth BPF, the BLI configuration is dominating the SWL. The reason for this alternation of SWL results from the alternation of the rotor wakes as shown in Figure 9b. Note that the left hand side contour plots of the mean velocity show the flow region close to the mixing plane for the BLI configuration and the right hand side contour plots show the same region for the Clean configuration. For the BLI configuration, the shape of the wakes is sharp, whereas a strong tip vortex region is visible for the Clean configuration. Due to the altered wakes, the second harmonic is more strongly excited for the Clean configuration compared to the BLI configuration. This does not hold for the third to fifth harmonic and may be explained by the larger wake structures responsible for the noise excitation. However, as the second harmonic is dominating the overall sound power level (OAPWL) of all BPF harmonic tones, this trend is secondary. The flow detachment in case of the Clean configuration results from the fact that the fan stage was designed to account for the inflow distortion [31]. Thus, the assumption of a Clean configuration results in an off-design operating condition showing a flow detachment at the rotor blades.

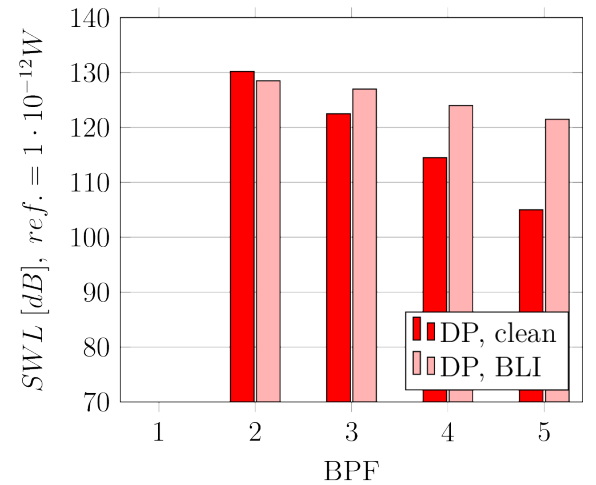

(a)
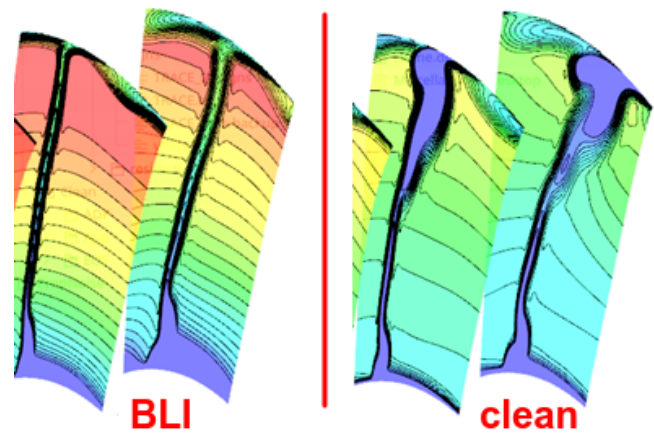

(b)

Figure 9. Results for generated tonal RSI noise and investigation of rotor wakes. (a) Sound power level (SWL) of tonal RSI noise with and w/o inflow distortion. (b) Investigation of rotor wakes close to the mixing plane with and w/o inflow distortion. Contour plots show the mean velocity. 
Finally, Figure 10 shows a result of the reconstruction of the real part of the sound pressure field at the engines inlet and outlet plane for the 2nd BPF. The modal structure of the sound pressure field for RSI noise, constituting by distinct modes (Tyler-Sofrin modes), is clearly visible.
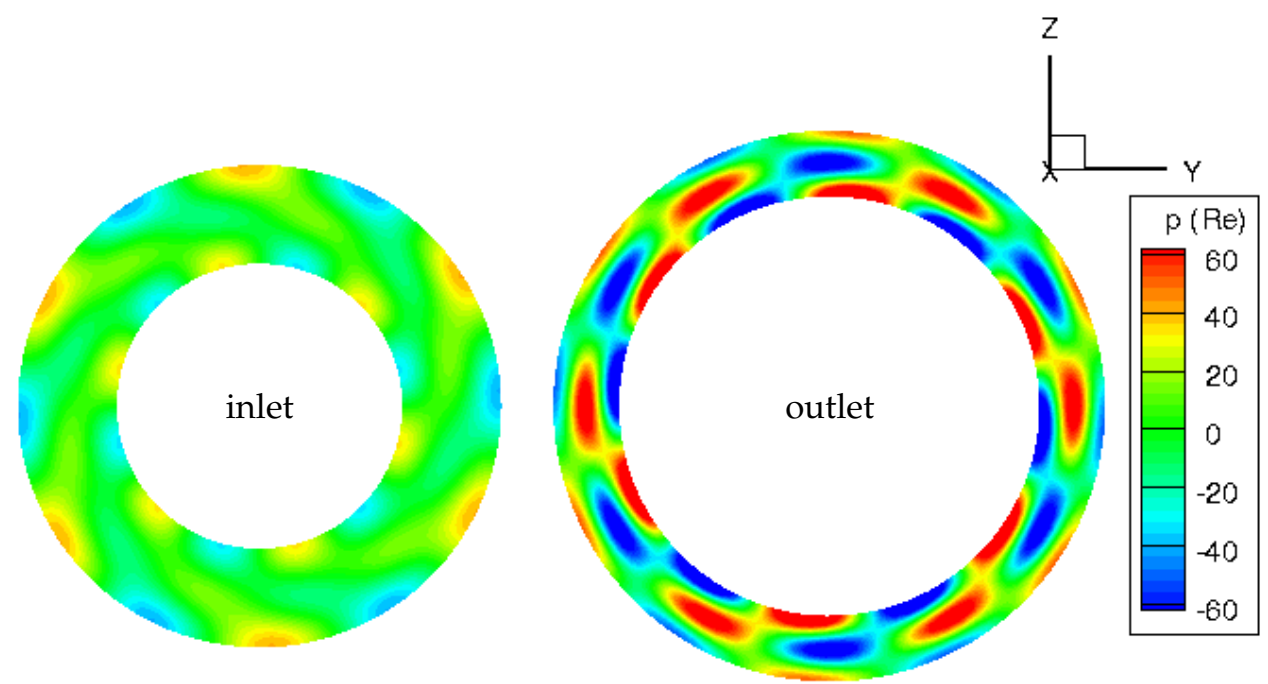

Figure 10. Real part of complex pressure in [Pa] for tonal RSI noise at inlet (left) and outlet (right) plane. 2nd BPF (1333.33 Hz). The modal structure of the sound field is clearly visible.

\subsection{Direct Acoustic Fields}

Using the engine noise boundary conditions as computed in Figure 10, the direct acoustic field was evaluated on the surface of the aircraft portion and on a microphones hemisphere. The hemisphere has a radius of $150 \mathrm{~m}$ with 64,800 nodes, and it is centered into the engine geometrical center. The $10 \mathrm{~m}$ portion of the aircraft tail is discretized with about 1 million of triangular elements corresponding to a maximum number of Points Per Wavelenght of 14 for the frequency $1333 \mathrm{kHz}$. In Figure 11a, the aircraft portion is visible with the engine inlet and outlet used as boundary condition. In Figure 11b, a particular of the mesh size is reported, corresponding to the junction between the vertical tail and the rear part of the fuselage (with red color the fuselage, green the vertical tail, and gray the engine nacelle).

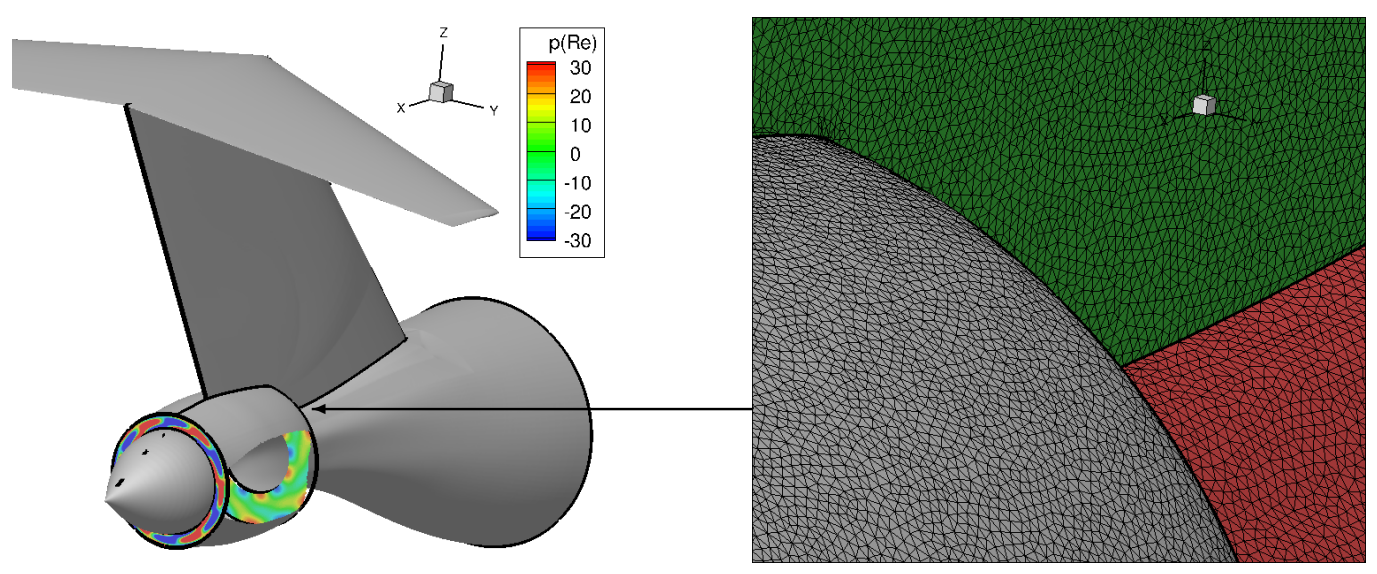

(a) Geometry with boundary conditions

(b) Mesh size

Figure 11. Aircraft portion geometry used in aeroacoustic simulation, with particular of the computational mesh grid. 
The engine noise boundary condition was computed for the case without boundary layer ingestion, labeled as "Clean", and for the case with engine boundary layer ingestion, labeled as "BLI". Note that the engine reference configuration was the boundary layer ingestion case, for which the fan stage is properly designed accounting for the presence of the inflow distortion. As a consequence, the Clean configuration results in an off-design case, with a flow detachment at the rotor blades. This is highlighted in Figure 9, where it is clearly visible that for the 2nd BPF the noise of BLI case is lower than Clean case. This behavior did not emerge for the other harmonics; however, the contribution of the second harmonic is prominent on the overall sound power level and drives the global noise results.

Sound Pressure Level (SPL) computed on the microphones hemisphere is shown in Figures 12 and 13, respectively, for the 2nd and 5th BPF. Note that the engine boundary layer ingestion case has a reduced noise level compared with the clean one at the 2nd BPF whereas the opposite behavior appears at the 5th BPF. As already mentioned, the boundary layer ingestion causes an alternation of the mean rotor wakes (in width and depth) that lead to the alternations in tonal rotor-stator-wake interaction noise leading to a noise reduction for the lowest frequency and to a noise increase for the higher ones.

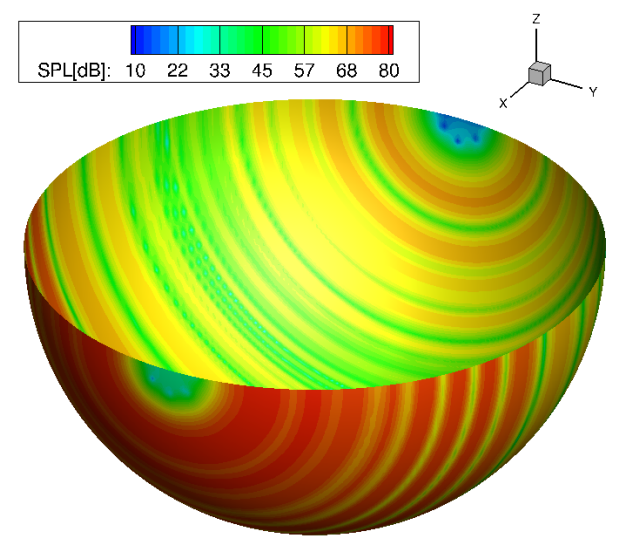

(a) Clean

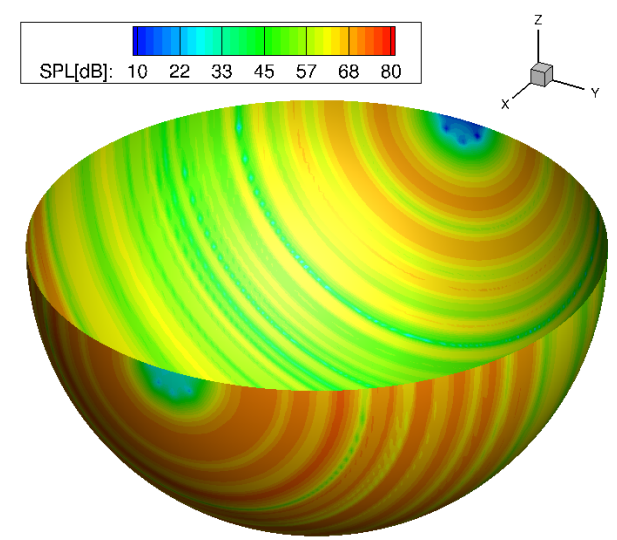

(b) BLI

Figure 12. Comparison of direct acoustic field on hemisphere, between the cases without (a) and with (b) boundary layer ingestion for the frequency $1333 \mathrm{~Hz}$.

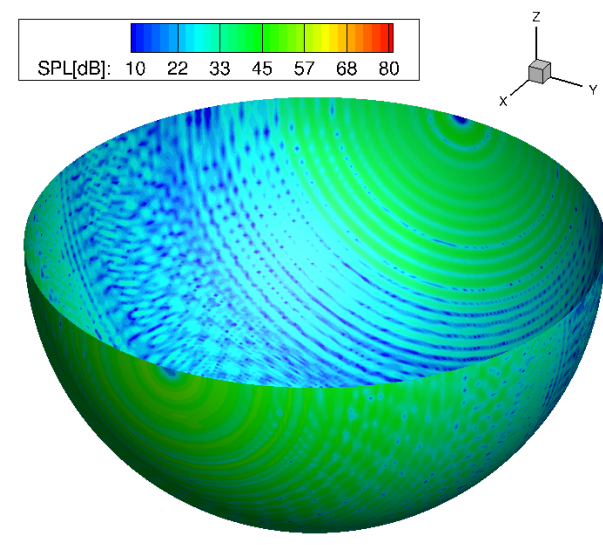

(a) Clean

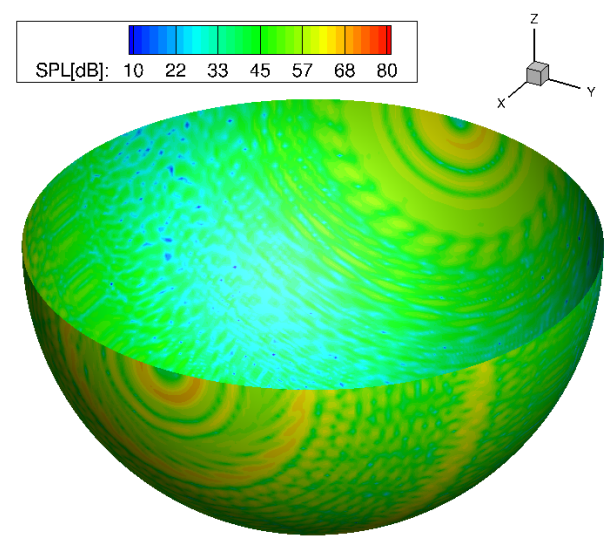

(b) BLI

Figure 13. Comparison of direct acoustic field on hemisphere, between the cases without (a) and with (b) boundary layer ingestion for the frequency $3333 \mathrm{~Hz}$.

A comprehensive comparison between the simulations with and without engine boundary layer ingestion is shown in Figure 14. Looking at the directivity along the X-axis 
(longitudinal direction), similar trends for the cases with and without BLI emerge at all frequencies. In particular, for both cases, the same shifting of the SPL levels emerge in the downstream direction, due to the presence of a uniform mean-flow. Moreover, note that the absolute values of the SPL levels decrease by increasing the frequency, even if this behavior is more pronounced for the non-BLI case than the BLI one.

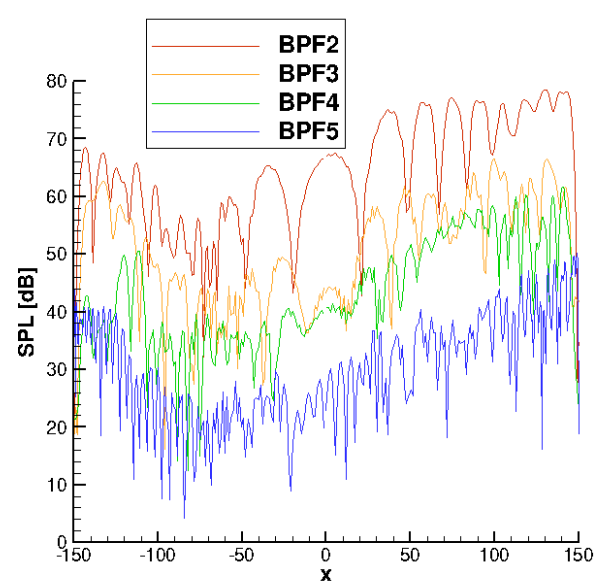

(a) Clean

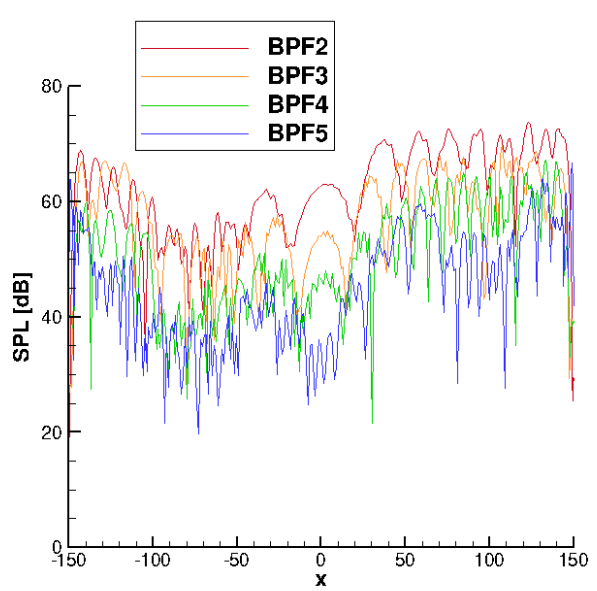

(b) BLI

Figure 14. Comparison of direct acoustic field between the cases without (a) and with (b) boundary layer ingestion, along the $\mathrm{Y}$ axis.

\subsection{Scattered Acoustic Fields}

Once the direct acoustic fields on the observers and on the scattering body have been computed, the scattered acoustic field can be computed according to the Equation (16). The same acoustic mesh of the aircraft surface already illustrated in the previous paragraph and in Figure 11 has been adopted. The computational analyses required a parallel computing with 8217 GB of RAM and 107 cores for the highest frequency, that corresponds to a nondimensional wave number, $\mathrm{kL}$, of around 610.6 , where $\mathrm{k}$ is the wave number and $\mathrm{L}$ is the characteristic dimension of the fuselage portion. This value was very close to the hardware limit of CIRA computational cluster, therefore it was unable to compute the scattered noise field for the 5 th BPF.

In Figure 15, the comparison among the BEM scattered field (left side) and the freefield (right side), computed on the microphones hemisphere, is reported in terms of SPL, for the Clean case and at the 2nd BPF. In Figure 16, the same comparison is illustrated for the BLI case. The comparisons show that the presence of the aircraft geometry modify the noise directivity pattern, especially in the middle region of the hemisphere, thus increasing the acoustic levels propagated under the engine.

For a better comparison among the two cases at all frequencies, the acoustic directivity along X-axis, in terms of SPL, are reported in Figure 17. Free-field (label DIRECT) and scattered field (label BEM), with (label BLI) and without (label CLEAN) engine boundary layer ingestion, are presented in Figure 17. As already mentioned, the contribution of the 5th BPF at $3333 \mathrm{~Hz}$ has been neglected due to the computational effort, being higher than the capability of the CPU cluster. However, a scattering effect similar to that observed in the lower range of frequencies would be reasonably expected also at the highest one. For all frequencies, the scattered noise field has higher sound pressure levels than the direct field in the middle of the hemisphere. For the lowest frequency, the BLI case has lower sound pressure levels than the clean one, while for the higher frequencies, an opposite behavior appears as already highlighted at source level in the previous paragraph. 

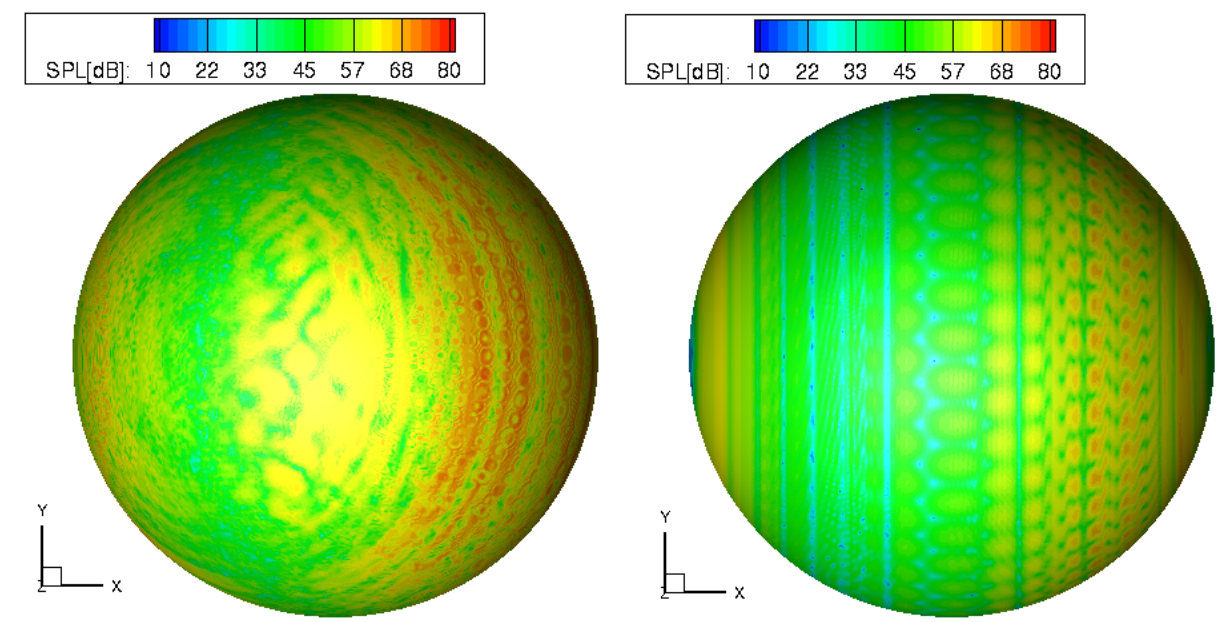

Figure 15. Scattered noise (BEM, left) results for frequency $2000 \mathrm{~Hz}$, Clean case, compared to Direct noise field (right).
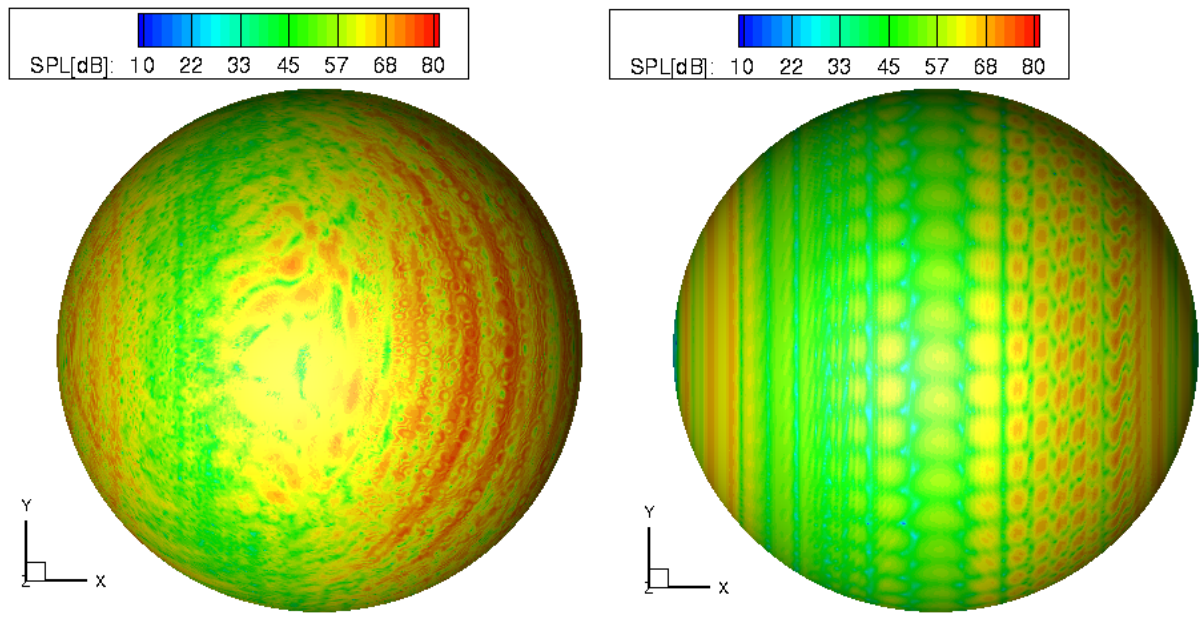

Figure 16. Scattered noise (BEM, left) results for frequency $2000 \mathrm{~Hz}$, BLI case, compared to Direct noise field (right).

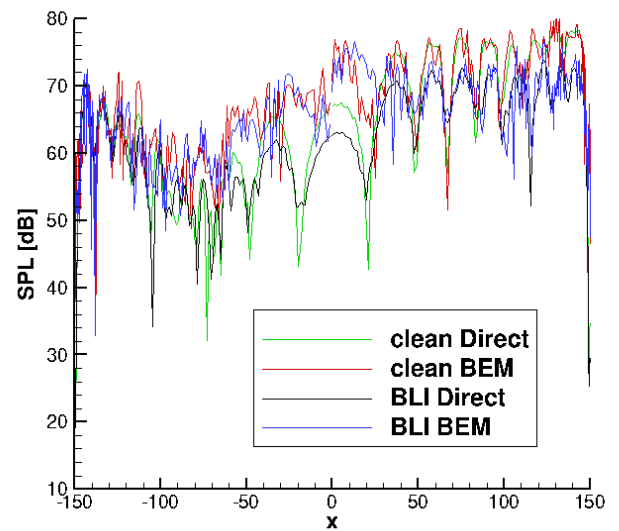

(a) $1333 \mathrm{~Hz}$

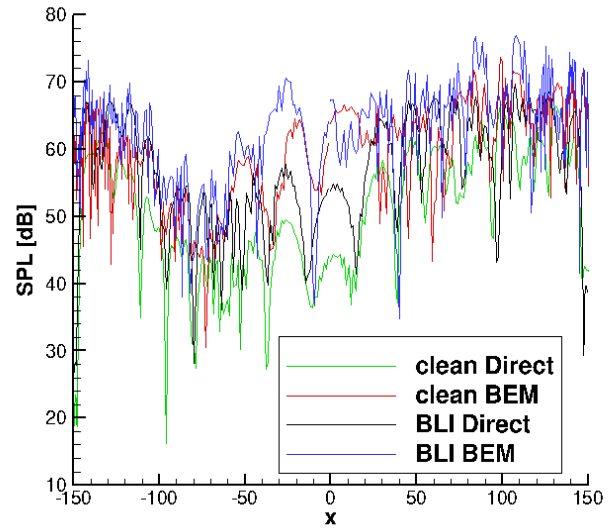

(b) $2000 \mathrm{~Hz}$

Figure 17. Cont. 


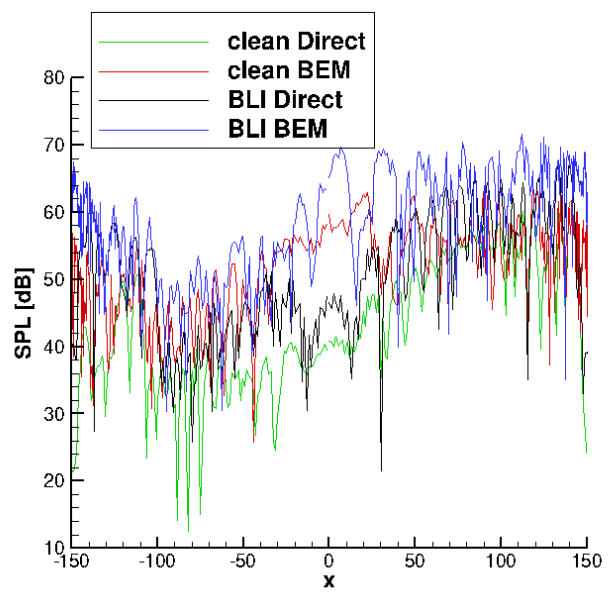

(c) $2666 \mathrm{~Hz}$

Figure 17. Comparison of scattered (BEM) results for three frequencies, along $\mathrm{X}$ axis.

\subsection{Acoustic Fields on the Ground}

The acoustic impact at ground level for the two engine cases has been evaluated. Following a standard approach [30], the time history of the Sound Pressure Level at selected microphones on the runaway has been computed (Figure 18) for a flyover condition, as long as the corresponding Sound Exposure Level (SEL) on the above-mentioned microphones and on a microphones carpet at $600 \mathrm{~m}$ of altitude. No atmospheric absorption and no soil reflection have been considered. The soil reflection contributes to increase the overall noise level, however the objective of the current work is to compare the two engine configuration, without considering the absolute noise value.

The ACO-ENV code presented in Section 3.2.3 uses as input noise field the scattered results and direct acoustic results computed for the frequency $1333 \mathrm{kHz}, 2000 \mathrm{kHz}$, and $2666 \mathrm{kHz}$, shown in the previous paragraph. Starting from those solutions, the code is able to evaluate the time history of SPL and OASPL values in selected points.

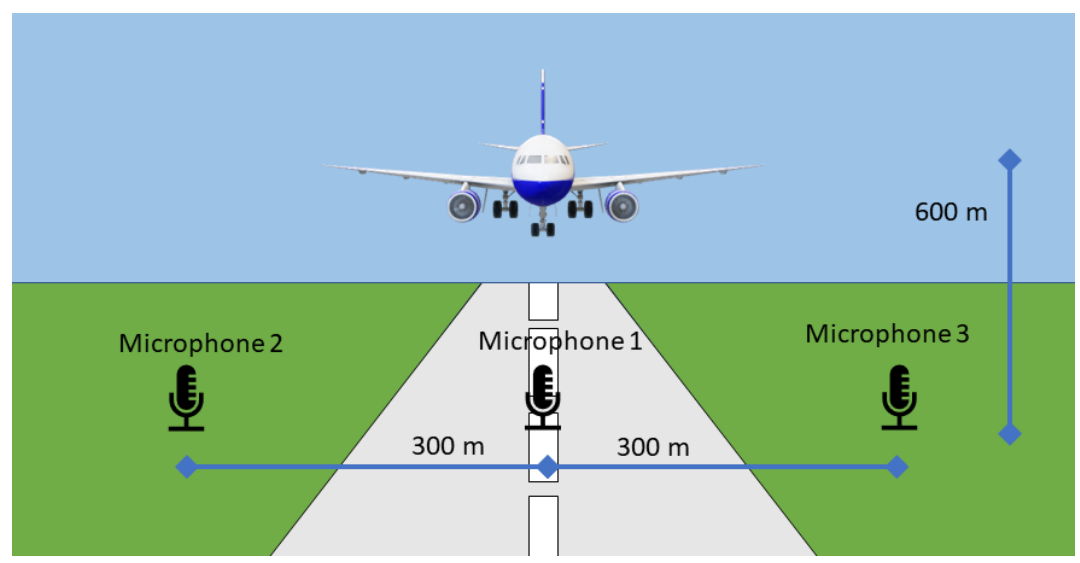

Figure 18. Flyover and measurement in three aligned points.

In Figure 19a, a comparison in terms of overall SPL time history is reported at the three microphones positions. Free- (label DIRECT) and scattered field (label BEM) have been compared for the BLI case (label BLI) and the clean one (label CLEAN). Referring to the central microphone, the installation effect is more evident than on the lateral microphones. The two lateral microphones show a slightly asymmetric behavior, though their position and the acoustic field are symmetrical with respect to the median vertical plane. This is due the absence of a symmetric boundary condition in the BEM calculation and due to the use of an unstructured mesh that is asymmetric with respect to the median vertical plane considered. 


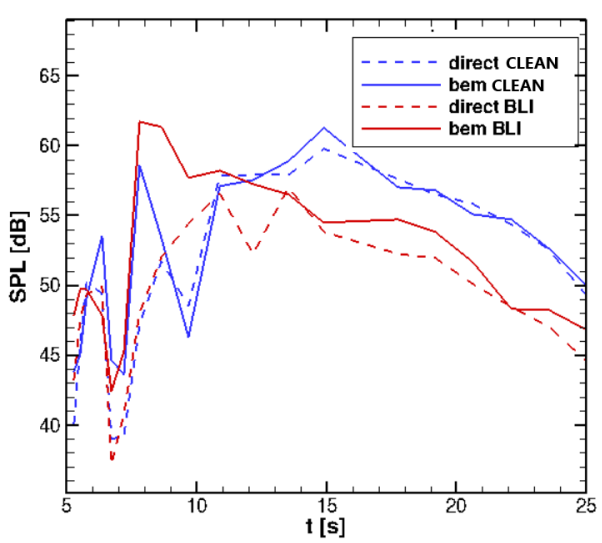

(a) Microphone 1

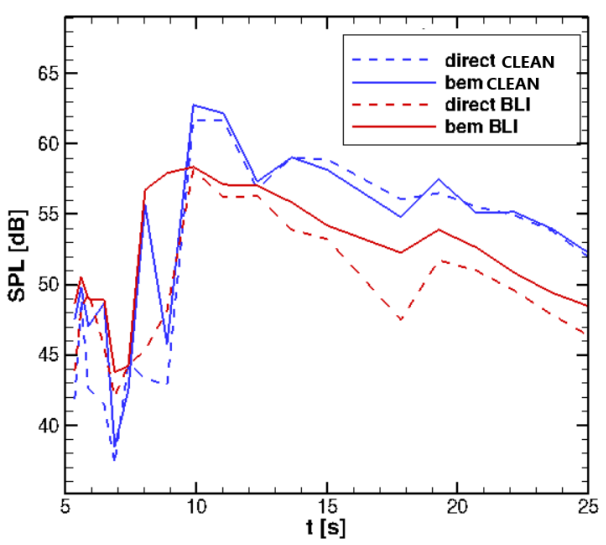

(c) Microphone 3

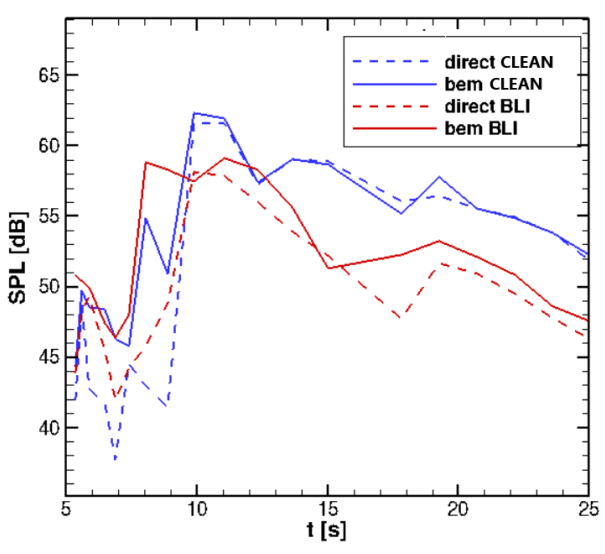

(b) Microphone 2

Figure 19. SPL time history on three locations on the runaway.

SEL for a single flyover event is finally reported at the three microphones positions in Figure 20, where the solid lines represent the results including the scattering effect and the dashed lines the direct counterpart. The difference in terms of SEL levels is clearly visible showing lower levels for the BLI case. However, this beneficial effect of the BLI case is reduced at ground level by the engine-aircraft installation. As already pointed out, the beneficial of the BLI case derives from the fact that the acoustic reference design point of the fan stage was considered by including the effect of the boundary layer ingestion.

Sound Exposure Levels have been also computed for a microphones carpet at an altitude of $600 \mathrm{~m}$. In Figures 21 and 22, the SEL carpet is shown, respectively, for the CLEAN case and BLI one. On the left side, results without installation effects are reported, while, on the right side, the corresponding ones with the acoustic installation effect. Comparing SEL carpets, the same conclusion of Figure 20 are deduced. For both free-field and scattering propagation, SEL carpet has lower values for BLI case than the one without BLI. Note that the propulsor-airframe installation effects poorly contribute to modify the noise field for the CLEAN case. This is due to the fact that the higher BPFs, that are the frequencies mainly contributing to the scattering effects, have much lower levels than the lowest BPF, as illustrated Figure 14. This behavior reflects in a small modification of the SEL carpet for the CLEAN case. For the BLI case, as shown on the right side of Figure 14, the highest BPFs have higher SPL values comparable to the 2nd BPF. These highest frequencies, being more affected by the scattering phenomena, contribute much more to the overall acoustic noise. As a consequence, the engine-aircraft installation effect partially degrades the benefit gained at source level by the BLI case. 


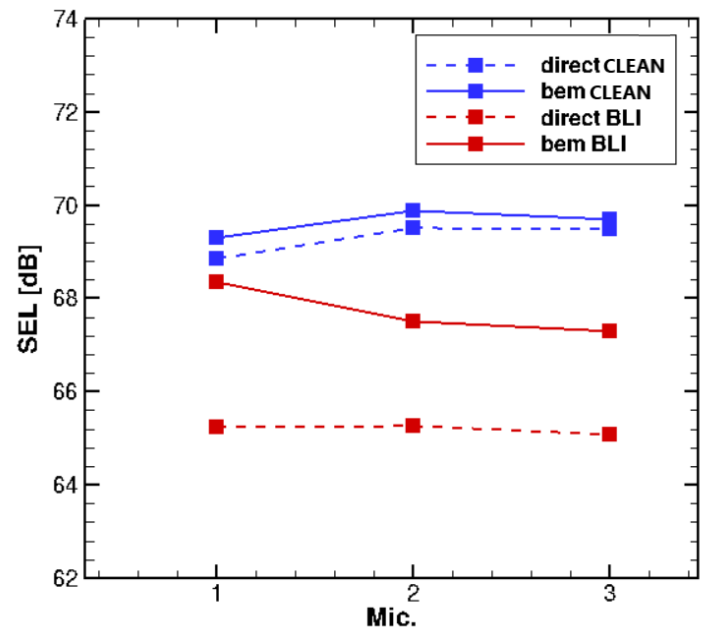

Figure 20. SEL for a single flyover for the three microphones.
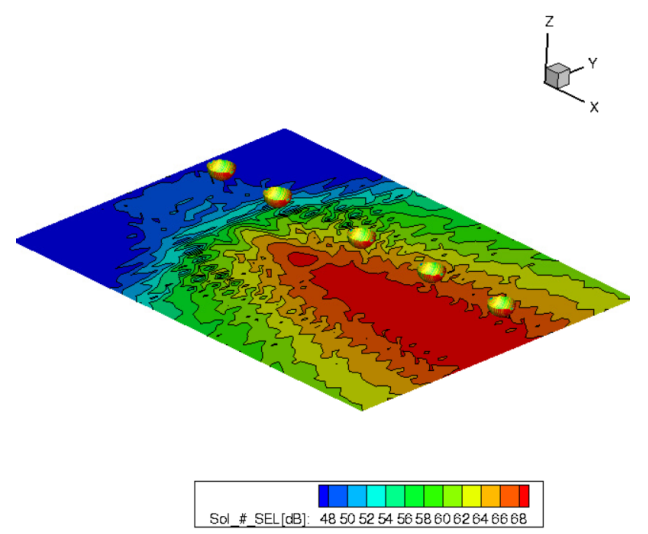

(a) Direct
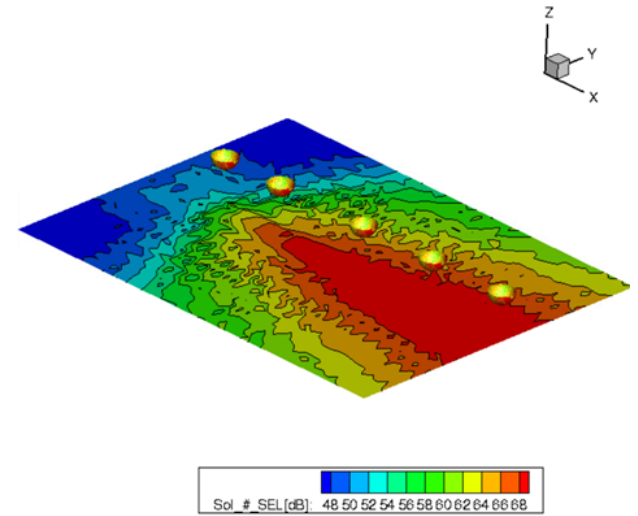

(b) Scattered

Figure 21. Comparison of Sound Exposure Level carpets. Clean case without acoustic installation effects (a) and with installation effects (b).
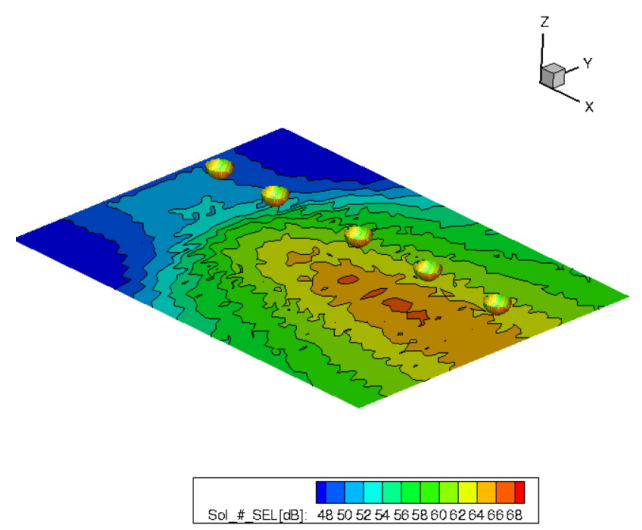

(a) Direct
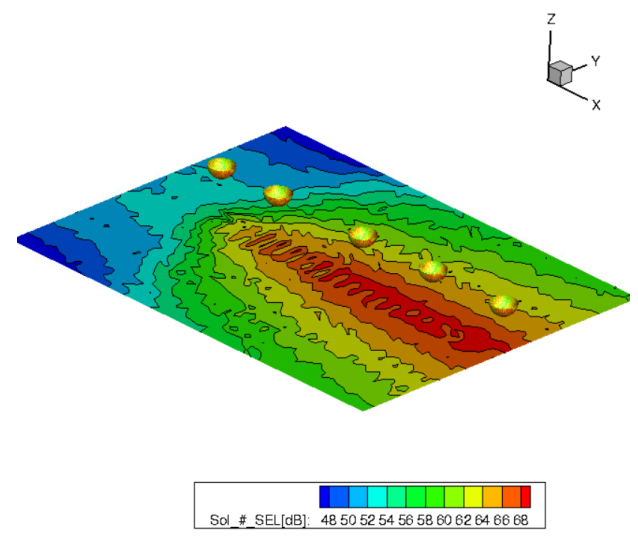

(b) Scattered

Figure 22. Comparison of Sound Exposure Level carpets. BLI case without acoustic installation effects (a) and with installation effects (b). 


\section{Conclusions}

As environmental sustainability is a key problem for the air transport, electric propulsion is giving promising answers to improve the aircraft efficiency. The opportunity of distributing the electric engines power on the aircraft leads to explore unconventional aircraft configurations as those involving engines partially embedded in the fuselage (BLI). Even though engine Boundary Layer Ingestion is a promising solution to reduce the aerodynamic drag, it causes a nonuniformity in the axial fan inflow, with aeroacoustic drawbacks. Using a mid-fidelity comprehensive Computational Aeroacoustics approach, the tonal Rotor-Stator Interaction noise problem was investigated with and without boundary layer ingestion. An engine noise source model was fed with a CFD solution of the fan stage and the in-duct acoustic field was computed. The fan stage was properly designed through the CFD approach to account for the inflow distortion, leading to a RSI under BLI with a lower 2nd BPF and greater higher BPFs. As the 2nd BPF dominates the overall sound power, RSI under BLI was less noisy than the clean one. The acoustic solution at the engine inlet and outlet was used as boundary condition of an Integral Boundary Element approach. The far-field propagation was computed on a microphones hemisphere surrounding the aircraft configuration including the acoustic masking effects due to the engine-fuselage installation. The generated hemispheres, representing the acoustic map of RSI with and without BLI and the fuselage masking effects, were exploited for a final assessment at ground level in terms of Sound Exposure Level. The environmental acoustic analyses confirmed the BLI overall noise levels are lower than the Clean one thanks to the proper design of the fan stage. However the effect of the engine-fuselage installation degraded the BLI benefit due to the reflection effects that play a major role at higher frequencies at which BLI is noisier than clean one. This result confirms the importance of properly designing the engine-fuselage integration taking into account also the masking effects in the early aircraft design stage for an effective noise reduction at ground level.

Author Contributions: Conceptualization, M.B.; Formal analysis, F.P. and M.S.; Investigation, F.P. and M.S.; Methodology, M.B. and M.S.; Project administration, M.B.; Software, M.B. and M.S.; Supervision, M.B.; Visualization, F.P. and M.B.; Writing original draft, F.P. and M.S.; Writing review and editing, F.P.. All authors have read and agreed to the published version of the manuscript.

Funding: This project has received funding from the Clean Sky 2 Joint Undertaking (JU) under grant agreement No 945583. The JU receives support from the European Union's Horizon 2020 research and innovation programme and the Clean Sky 2 JU members other than the Union.

Institutional Review Board Statement: Not applicable.

Informed Consent Statement: Not applicable.

Data Availability Statement: The data presented in this study are available on request from the corresponding author. The data are not publicly available due to Clean Sky 2 Joint Undertaking copyright regulation.

Acknowledgments: The authors acknowledge the support given by the CIRA colleagues Davide Cinquegrana and Pierluigi Vitagliano for the definition of the geometries, and Pierluigi Iannelli for the project management support. The authors also acknowledge the support given by DLR colleagues Maximilian Mennicken and Rainer Schnell for the propulsor design.

Conflicts of Interest: The authors declare no conflict of interest. The results, opinions, conclusions, etc. presented in this work are those of the author(s) only and do not necessarily represent the position of the JU; the JU is not responsible for any use made of the information contained herein. 


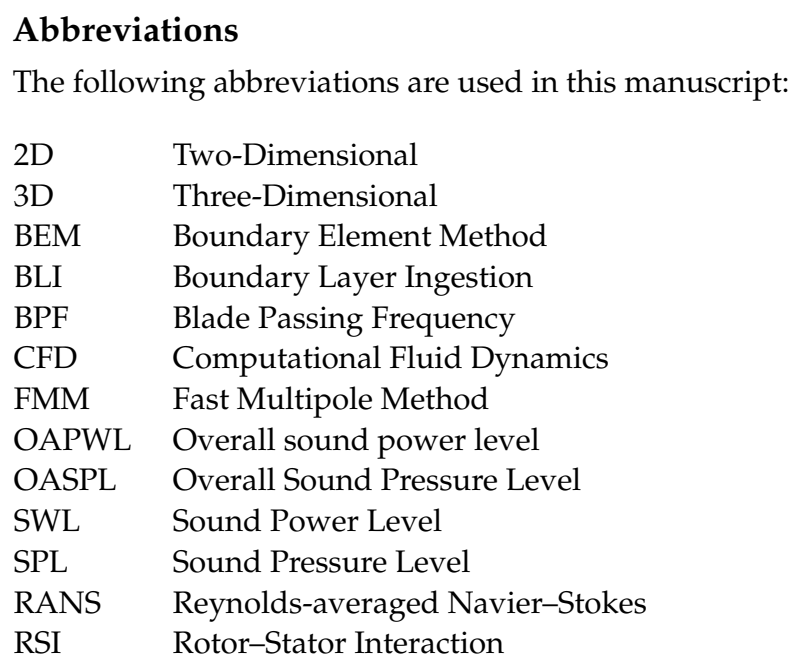

\section{References}

1. EU. Flightpath 2050, Europe's Vision for Aviation; Report of High-Level Group on Aviation Research; Publications Office of the EU: Luxembourg, 2012. [CrossRef]

2. Guo, Y.; Thomas, R.H.; Clark, I.A.; June, J.C. Far-Term Noise Reduction Roadmap for the Midfuselage Nacelle Subsonic Transport. J. Aircr. 2019, 56, 1893-1906. [CrossRef]

3. Wiart, L.; Atinault, O.; Boniface, J.C.; Barrier, R. Aeropropulsive performance analysis of the NOVA configurations. In Proceedings of the 30th Congress of the International Council of the Aeronautical Sciences, Daejeon, Korea, 26-30 September 2016.

4. Geiselhart, K.; Daggett, D.; Kawai, R.; Friedman, D. Blended Wing Body Systems Studies: Boundary Layer Ingestion Inlets with Active Flow Control. NASA Contract Report; NASA/CR-2006-214534. 2004. Available online: https://ntrs.nasa.gov/citations/ 20070006754 (accessed on 9 November 2020).

5. Romani, G.; Ye, Q.; Avallone, F.; Ragni, D.; Casalino, D. Fan Noise Boundary-Layer Ingestion Installation Effects for NOVA Aircraft Configuration. In Proceedings of the 25th AIAA/CEAS Aeroacoustics Conference, Delft, The Netherlands, 20-23 May 2019. [CrossRef]

6. Guo, Y.; Burley, C.L.; Thomas, R.H. On Noise Assessment for Blended Wing Body Aircraft. In Proceedings of the 52nd Aerospace Sciences Meeting, National Harbor, MD, USA, 13-17 January 2014. [CrossRef]

7. Chen, Z.; Zhang, M.; Chen, Y.; Sang, W.; Tan, Z.; Li, D.; Zhang, B. Assessment on critical technologies for conceptual design of blended-wing-body civil aircraft. Chin. J. Aeronaut. 2019, 32. [CrossRef]

8. Welstead, J.; Felder, J.L. Conceptual Design of a Single-Aisle Turboelectric Commercial Transport with Fuselage Boundary Layer Ingestion. In Proceedings of the 54th AIAA Aerospace Sciences Meeting, San Diego, CA, USA, 4-8 January 2016. [CrossRef]

9. Moreau, A. A Unified Analytical Approach for the Acoustic Conceptual Design of Fans of Modern Aero-Engines. Ph.D. Thesis, Technical University of Berlin, Berlin, Germany, 2017.

10. Staggat, M.; Moreau, A.; Guerin, S. Analytical prediction of boundary layer ingestion noise for an integrated turbofan. In Proceedings of the 26th International Congress on Sound and Vibration (ICSV), Montréal, QC, Canada, 7-11 July 2019.

11. Becker, K.; Heitkamp, K.; Kügeler, E. Recent Progress In A Hybrid-Grid CFD Solver For Turbomachinery Flows. In Proceedings of the 5th European Conference on Computational Fluid Dynamics (ECCOMAS CFD), Lisbon, Portugal, 14-17 June 2010.

12. Jaron, R. Aeroakustische Auslegung von Triebwerksfans Mittels Multidisziplinärer Optimierungen. Ph.D. Thesis, Technical University of Berlin, Berlin, Germany, 2018.

13. Moreau, A.; Guerin, S. Similarities of the free-field and in-duct formulations in rotor noise problems. In Proceedings of the 17th AIAA/CEAS Aeroacoustics Conference (32nd AIAA Aeroacoustics Conference), Portland, OR, USA, 5-8 June 2011. [CrossRef]

14. Tapken, U. Analyse und Synthese Akustischer Interaktionsmoden von Turbomaschinen. Ph.D. Thesis, Technical University of Berlin, Berlin, Germany, 2015.

15. Lighthill, M.J.; Newman, M.H.A. On sound generated aerodynamically I. General theory. Proc. R. Soc. Lond. Ser. A. Math. Phys. Sci. 1952, 211, 564-587. [CrossRef]

16. Lighthill, M.J. On sound generated aerodynamically II. Turbulence as a source of sound. Proc. R. Soc. Lond. Ser. A. Math. Phys. Sci. 1954, 222, 1-32. [CrossRef]

17. Howe, M.S. Contributions to the theory of aerodynamic sound, with application to excess jet noise and the theory of the flute. J. Fluid Mech. 1975, 71, 625-673. [CrossRef]

18. Pierce, A.D. Wave equation for sound in fluids with unsteady inhomogeneous flow. Acoust. Soc. Am. J. 1990, 87, 2292-2299. [CrossRef]

19. Morris, P.J.; Farassat, F. Acoustic Analogy and Alternative Theories for Jet Noise Prediction. AIAA J. 2002, 40, 671-680. [CrossRef]

20. Wu, T.; Lee, L. A Direct Boundary Integral Formulation For Acoustic Radiation In A Subsonic Uniform Flow. J. Sound Vib. 1994, 175, 51-63. [CrossRef] 
21. Guo, Y. Computation of Sound Propagation by Boundary Element Method. NASA Contract Report; NAS1-00086-A003. 2005. Available online: https://ntrs.nasa.gov/citations/20080030156 (accessed on 14 December 2020).

22. Barbarino, M. Aeroacoustic Methods for Low-Noise Technologies Design. Ph.D. Thesis, University of Naples "Federico II", Naples, Italy, 2013. [CrossRef]

23. Crighton, D.G.; Dowling, A.P.; Ffowcs-Williams, J.E.; Heckl, M.; Leppington, F.G.; Bartram, J.F. Modern Methods in Analytical Acoustics Lecture Notes. J. Acoust. Soc. Am. 1992, 92, 3023. [CrossRef]

24. Barbarino, M.; Bianco, D. A BEM-FMM approach applied to the combined convected Helmholtz integral formulation for the solution of aeroacoustics problems. Comput. Methods Appl. Mech. Eng. 2018. [CrossRef]

25. Wu, T.W.; Seybert, A.F. A weighted residual formulation for the CHIEF method in acoustics. J. Acoust. Soc. Am. 1991, 90, 1608-1614. [CrossRef]

26. Liu, J.; Chen, Y.; Maisog, J.M.; Luta, G. A new point containment test algorithm based on preprocessing and determining triangles. Comput. Aided Des. 2010, 42, 1143-1150. [CrossRef]

27. Lucas, M.J.; Marcolini, M.A. Rotorcraft Noise Model. NASA Tech Report. 1997. Available online: https://ntrs.nasa.gov/ citations / 20040110391 (accessed on 14 December 2020).

28. Gopalan, G. Quasi-Static Acoustic Mapping of Helicopter Blade-Vortex Interaction Noise. Ph.D. Thesis, University of Maryland, College Park, MD, USA, 2004. Available online: https:/ / drum.lib.umd.edu/handle/1903/1757 (accessed on 19 October 2020).

29. SAE-International. Standard Values of Atmospheric Absorption as a Function of Temperature and Humidity; SAE ARP866B; Society of Automotive Engineers: Warrendale, PA, USA, 2012. [CrossRef]

30. SAE-International. Procedure for the Calculation of Aircraft Noise in the Vicinity of Airports; SAE AIR1845A; Society of Automotive Engineers: Warrendale, PA, USA, 2012. [CrossRef]

31. Mennicken, M.; Hollmann, C.; Staggat, M.; Schnell, R.; Silberhorn, D.; Arzberger, M.J.; Eichner, F.; Winkelmann, P. Preliminary Fan Design for a Full Annulus BLI Propulsor. In Proceedings of the Deutscher Luft- und Raumfahrtkongress 2020, Aachen, Germany, 1-3 September 2020.

32. Silberhorn, D.; Hollmann, C.; Mennicken, M.; Wolters, F.; Eichner, F.; Staggat, M. Overall Design and Assessment of Aircraft Concepts with Boundary Layer Ingesting Engines. In Proceedings of the Deutscher Luft- und Raumfahrtkongress 2019, Darmstadt, Germany, 30 September-2 October 2019.

33. Silberhorn, D.; Arzberger, M.J.; Wolters, F.; Hollmann, C.; Mennicken, M.; Iwanizki, M. Multidisciplinary Investigation of Partially Turboelectric, Boundary Layer Ingesting Aircraft Concepts. In Proceedings of the AIAA Scitech 2020 Forum, Orlando, FL, USA, 6-10 January 2020. 